\title{
Krämer Jürgen: Intervertebral disk diseases; causes, diagnosis, treatment and prophylaxis
}

\author{
Thieme Verlag, New York, Stuttgart, 2008, 366 pp, number figures, \\ Hardcover, Euro (D) 139.95 CHF 232.00, ISBN: 978-3-13-582403-1
}

\author{
Pierre Kehr
}

Received: 28 February 2010 / Accepted: 1 March 2010 / Published online: 14 March 2010

(C) Springer-Verlag 2010

The fundamental role of the disk in spinal motion and the knowledge of its mode of biological deterioration in time made important progress that partly justifies the 3rd edition of this work. The contents are particularly exhaustive: history, epidemiology, anatomy, physiology, biomechanics, degenerative and no degenerative disk diseases, cervical, thoracic and lumbar syndromes, pain, and natural history. The last four chapters are interesting and practical: the spine and the mind, back school, sports, and medico-legal assessment. The authors succeed in reconciling exhaustiveness and synthesis; thanks to summary tables and an excellent iconography. The bibliography often has Germanic prevailing and is very astutely given on an Internet site, which makes it possible to reduce the size of the work.

Pathology of the intervertebral disks constitutes certainly the first cause of consultation in spinal degenerative diseases and thus interests for this reason of many actors of the management of this pathology: functional general doctors, rheumatologists, rehabilitation doctors, and surgeons. This book, very successful, will fill certainly a great number of them.

Laurent Balabaud Paris (France)

P. Kehr $(\bowtie)$

SOTEST, Strasbourg, France

e-mail:kehrpier@aol.com 